\title{
Engineers as Poets \\ The Need for Poetry Contests in Colleges of Engineering
}

\author{
Craig James Gunn \\ Department of Mechanical Engineering \\ Michigan State University \\ East Lansing, MI
}

\begin{abstract}
ABET's new requirements for accreditation give a clear indication that written communication is of tantamount importance in the education of undergraduate engineers. It is interesting to note that previous to EC 2000, communication in all its forms did not merit more than a few lines hidden away in the ABET document. With its newly gained prominence, educators are scrambling to make sure that their programs contain the right blend of technical and communication skill training. While this training focuses on adequate lab reports, grammatical correctness, and suitable vocabulary, there are other ways that might help to interest students in the communication needed in their profession. Three years ago, as a means to initiate more communication within the College of Engineering at Michigan State University, a college-wide poetry contest was instituted to coincide with Engineering Week. The prime motivation behind the contest was to show the creative talent of the engineering students, but it also served a needed purpose of providing a visible validation for their sometimes-secretive writing activities.
\end{abstract}

The particulars of the poetry contest, assessment by writers and readers of the submitted works, and an overview of why poetry contests should be instituted in all colleges and schools of engineering is detailed in the paper. Since the contest now attracts entries from students (both college and high/middle school), faculty, staff, and alumni it is clear that this one simple genre can be used as a means to get students, especially engineering students, to write with enjoyment as the focus.

'Variety's the spice of life, that gives it its flavor." These lines in "The Task, I" by William Cowper (English poet 1731-1800) reflect an attitude that must he fostered in the minds of engineers. No man is an island, and no field of study can divorce itself from the activities, interests, and positive reinforcement of divergent areas of instruction. Students who become embroiled in the quest for a degree in any of the engineering areas can quickly close the doors to many of the more liberal pursuits. The feeling exists that any time spent on "non-engineering" pursuits is not beneficial to the career. Efforts must be made to include in the educational structure of every engineer ample connections to the world of the humanities.

Too many engineers go through their college or university careers unaware that many of their peers studying fluids, circuits, controls, composites, or calculus have vast experience in the liberal arts. These talents and interests lie hidden while the technical courses are taken and technical knowledge is gained. It is important to the rounded education of engineers that an effort 
be made to bring to light the liberal interests of engineers. Age-old stereotypes that influence the way that engineers perceive themselves need to be investigated, modified, and in many cases destroyed.

When the science revolution took place in the $1700 \mathrm{~s}$, the movement to divorce the scientific world from the arts was loudly applauded by liberal studies activists. Science was trying to carve its place in the world and, therefore, had other issues to consume its time, Complaints over the past decades have reflected upon this separation of disciplines. We have been deluged with "right brain, left brain" concerns, with cries that "engineers cannot communicate", and with the whole smokescreen of what is perceived to be the "stereotypical engineer." We can decry these attitudes, but many are ingrained into the society in which we live and work. While the public's perception of engineers may require a vast reeducation, it is with the engineers that the first steps must be taken to change the incorrect vision.

The comments made here will not deal with the vast battle lines that involve the world outside of engineering. To cover that issue would take much greater space than can be allowed in this work. The area that will be investigated approaches the issue from the inside by targeting the engineering faculty, support staff, and students.

No visible change can take place in the attitudes of people if interest and a willingness to discuss are not present. In order for the attitudes of the world to change, engineers must first believe that there is no wall between the sciences and the humanities. As engineers grow in their realization that the humanities do hold an important place in their lives then the word will reach out to the masses of people outside the engineering disciplines. Interested parties in every engineering department should be functioning as catalysts to the thoughts of groups like the Liberal Education Division of The American Society of Engineering Education. They should he working to make every student, staff, and faculty member aware of the liberal education interests of everyone connected to engineering.

One finds a very interesting situation when one approaches the issue of the humanities and its connection to engineering. The stereotypical vision of the engineer stated above is rampant in both the engineering community and the world outside engineering. It is enlightening to note, though, that the stereotype is only a superficial belief among the vast majority of engineers. It appears to be necessary for many to foster this belief in order to keep the engineering area pure from liberal notions. The importance of the technical education is somehow enhanced by the fact that it is not connected to the arts and letters curriculum. When one sits down with engineers in a non-threatening environment where true feelings can be expressed, a different impression is expressed. Students begin to speak about the instruments that they play and the particular level of competence that they have achieved in the musical world. When discovered working on the computer, students will blush when they speak of the poetry that they write, the most recent play that has been penned, or the latest collection of short stories that have been produced. In many cases, this admission seems to be something that should he left hidden in a veil of secrecy.

Students never seem ready to admit to a sharing of liberal ideas, needs, and wants. This desire to submerge these interests in areas other than engineering demonstrates the need to revitalize the education of future engineers. 
All the above activities may be of interest to those who believe that elements of the humanities are a vital part of an engineer's education. The problem exists when we approach the typical student body and inform it that the humanities should be investigated, utilized, and made a part of an engineer's life. Here the necessity is to make a case for the unification of the technical and liberal sides to education. The intricacy of musical pieces, the knowledge that can be gained from working carefully through a text, or the meticulous effort that needs to taken in painting a work of art are activities that complement the direction that engineers commonly follow in gaining their knowledge. Engineers are meticulous. They strive for clarity and conciseness, and their research requires exacting pursuit until every contingency is addressed. The creative mind presents these same requirements. As engineers delve into the world of liberal arts they will find the connections that unify the two areas of study. The catalyst that can begin this process is as close as the department in which they study. Conversation leads to discussion. Discussion can open wide the doors. Here we enter the world of poetry and its place in the College of Engineering at Michigan State University.

In the first year of the poetry contest, approximately 50 students, faculty, and staff submitted almost 100 poetical works that covered engineering themes and the more liberal areas of love, friendship, and heartache. During a three-week period, the submissions flowed freely and the excitement grew in the college. Some awaited the announcement of winners, and some chose to await the end of the contest to see if engineers could really produce quality material. It did not take long for the results to show both the creativity and the depth of ability in the engineers. The following poem by Joe Kramer shows a fun loving ability to investigate the language and give it life.

\section{My Poem Would Eat Nothing}

Joe Kramer

Like a stubborn little child acquiring new tastes.

I try to feed him

metaphors, verbs, nouns, but they all oozed out.

How about a fresh batch of adjectives?

No.

Well I am running out of options.

How about some pro-nouns?

Everybody loves pro-nouns.

No,

there they go dribbling off the page and onto the floor.

I have no idea what to try next, but maybe you will be ready tomorrow.

Here Julie Richards a mechanical engineering student opens her heart in a poem with no title, while Steve Miller presents a more lighthearted presentation. 


\section{No Title}

Julie Richards

Having children scares her.

Terrifies her.

She trembles at the thought.

Dirty clothes and faces and diapers

And cuts and bruises and scrapes

And pushing and sweating and nightmares

She doesn't want any of this.

But she must have it.

Her body tells her

And her head tells her

And husbands and

Mothers and sisters and fathers

And the neighbors that live

Behind them in the odd blue house

That is strangely intriguing.

Determination over comes her.

Drives her.

And suddenly it happens everywhere.

In the bedroom and the dining room

And in kitchens and bathrooms

And in the back of the car

They borrowed to drive down to

Connecticut to visit friends

They haven't seen

In ages.

So then it happens.

The plus stares at her.

She sobs.

Everybody is calling and

Cards and flowers and balloons

And presents that are strangely intriguing

Even though they are lurid in their pinks' and blues' and yellows.'

She becomes everything

All at once.

And all against her will.

\section{Extreme Engineering}

Steve Miller

The Art of Engineering

Taken to the Extreme 


With Math Beyond
What Newton Dreamed
Reimann Sums, Taylor Series,
And Vectors Galoo
Yikes what will all this come to?
No artist is solo -
We work in teams
Building Slinkys and Spacecraft
There isn't anything that we can't do!
Breaking barriers and withstanding failure we
Change the world with products and plasma goo!
Bringing our dreams past all known extremes.

In 2002, the number of entrants increased to over 75 with an added excitement that showed that students were not only interested in submitting work but experiencing what others had written. The range of work increased and the creativity continued to grow. It was especially interesting to see students reading those works that were deemed winners in the contest when they were displayed in the lobby of the Engineering Building. There was a quiet reserve in the lobby turned reading room. Some students were even heard to ask other students "to quiet down so they could truly enjoy the reading." Poetry had become something that was not the property of those liberal education majors on the other side of campus. Poetry was a part of engineering as much as math and science. The depth of understanding and ability to present ideas improved.

\section{Nothing but a Yellow Pepper}

Scott Douglas

Once again I have passed on the opportunity to cook

In exchange for valuable time in this place

As I walk down the halls my eyes scan the papers that adorn the walls

They all seem the same

Roommates wanted, car for sale......but wait

Like a needle in the haystack there lies an interesting proposal

"Come to the meeting for Free pizza"

It immediately draws my attention

My mind races with a million questions

Is this a trap? Who are these sharks luring me in?

Will I survive their Jedi mind tricks to make me join their secret society?

If I go how many slices will I get and will it be worth it?

This is were my engineering skills have prepared me

I grab for my TI-86 and start to calculate

Checking a standard distribution curve I find that the average meeting has 50 slices

Not bad considering the average person consumes 2.4 slices per meeting 
Total number in attendance $=12$ members +10 attendees +1 straggler

After some Venn Diagrams and Eigenvectors I figure I can get $32.99 \mathrm{in}^{2}$ worth of pizza

My heart begins to race and my mouth waters

I desperately search for a room number on the colored paper

As soon as I see it I am off

I am almost there when I screech to a halt

I haven't taken into account the type of pizza!

Considering this group's taste I figure they will go cheap

I quickly pull out my calculations again and continue

The pizza will be thinner than paper so my consumption volume will be roughly 8.25 in $^{3}$

This may not be worth it

After some minutes of decisive thinking it hits me

I quickly draw a Design Matrix and give my problem the appropriate weighting factors

Highest score wins here so it's all or nothin'

Should I stay or should I go?

With a score of 92.5 to 67 the winner is clear

I run to the meeting and try to sneak in unnoticed

All eyes are on me but I don't care I'm hungry

I walk over to the pizza boxes for my 2.4 slices

I open the top

Nothing but a yellow pepper

\section{The Ph.D. Student's Dilemma}

\section{Sean Davis}

A grad student was running some tests, the results of which were leaving him vexed.

The thermal diffusivity

of bovine artery

was higher than those cited in texts!

He checked over each boundary condition.

Locating error was his personal mission.

The device was realigned

and the model was redesigned;

still the aorta showed high heat transmission.

Former students and peers were contacted and suggestions were subsequently enacted.

To account for some heat transmitted thru the meat at this rate which is quicker than expected.

Still the data ran a little bit high

The grad student thought he would cry!

No amount of statistics 
short of something sadistic

would reduce the error in squared-chi.

What is the cause of this horrible lament

which caused the alpha to ascent?

It was arteriosclerosis,

which caused tissue necrosis,

no wonder that cow sported a stent!

\section{Everything Changes}

Katie Adams

Teardrops splatter and

pictures fade away.

Memories grow dim,

love switches names.

Everything changes

as life passes by.

Candles flicker

in the face of time.

As the new year unfolds, the contest slated to begin in mid January has already received 20 submissions from 20 new young poets. The contest or experience in other writing has become something that will continue to draw more and more writers who will expand the experiences that they have with the written language. As they investigate this newfound area, they will see improvement in their ability to produce good engineering text.

Poetry allows engineers to produce text that is outside the normal technical production. These engineers can let their creative juices flow within both technical and non-technical areas, experimenting with language and structure. Poetry allows the engineer an avenue for expression in a very technical existence.

\section{Conclusions}

Writing, speaking, thinking, and listening in areas other than engineering are activities that can easily be sponsored and perpetuated in engineering departments. Poetry contests provide a means to open up such avenues for communication. Students made aware of the need to expose their liberal talents and interests to their fellow engineers will bring to engineer a whole new area of creativity, creativity that is at the heart of all true engineers. Faculty and staff members should utilize any means possible to draw connections between engineering and the liberal arts. At the simplest level it is an awareness issue. As more individuals are made aware of the mutual interests of their colleagues, the separation of the liberal arts and the sciences will shrink. With this shrinkage will come a greater awareness on the part of the rest of the world and with it a firmer commitment to see the whole person and not the stereotype.

CRAIG JAMES GUNN is the Director of the Communication Program in the Department of Mechanical Engineering. Author of numerous papers on communication within engineering departments, he also spends time with co-op students helping to prepare them for their working semesters during their college careers. With degrees in English, he holds a unique place with which to provide support to engineering students as an in-house guide to communication. 